\title{
Amorphous Silicon-Germanium Films with Embedded Nanocrystals for Thermal Detectors with Very High Sensitivity
}

\author{
Cesar Calleja, Alfonso Torres, Pedro Rosales-Quintero, and Mario Moreno \\ National Institute of Astrophysics, Optics and Electronics (INAOE), Electronics Department, \\ Laboratory of Innovation in MEMS (LI-MEMS), 72840 Tonantzintla, PUE, Mexico
}

Correspondence should be addressed to Mario Moreno; mmoreno@inaoep.mx

Received 19 October 2015; Revised 6 January 2016; Accepted 11 January 2016

Academic Editor: Wen Zeng

Copyright (C) 2016 Cesar Calleja et al. This is an open access article distributed under the Creative Commons Attribution License, which permits unrestricted use, distribution, and reproduction in any medium, provided the original work is properly cited.

\begin{abstract}
We have optimized the deposition conditions of amorphous silicon-germanium films with embedded nanocrystals in a plasma enhanced chemical vapor deposition (PECVD) reactor, working at a standard frequency of $13.56 \mathrm{MHz}$. The objective was to produce films with very large Temperature Coefficient of Resistance (TCR), which is a signature of the sensitivity in thermal detectors (microbolometers). Morphological, electrical, and optical characterization were performed in the films, and we found optimal conditions for obtaining films with very high values of thermal coefficient of resistance (TCR $=7.9 \% \mathrm{~K}^{-1}$ ). Our results show that amorphous silicon-germanium films with embedded nanocrystals can be used as thermosensitive films in high performance infrared focal plane arrays (IRFPAs) used in commercial thermal cameras.
\end{abstract}

\section{Introduction}

Detectors and infrared focal plane arrays (IRFPAs), also known as thermal detectors (or thermal FPAs), are used in a wide variety of applications as industrial, medical, security, surveillance, and military [1-4]. In a thermal detector, the incident infrared (IR) radiation is absorbed by a thermosensitive material, resulting in a change of one of its physical properties, which is used to get an electrical signal output. In thermal detectors, the thermosensing material must have a high sensitivity to temperature and must be compatible with the standard silicon ( $\mathrm{Si}$ ) CMOS fabrication process, for low cost manufacture and integration with a Si CMOS readout integrated circuit (ROIC).

The temperature sensitivity of a material is given by its Temperature Coefficient of Resistance (TCR), which is related to the activation energy $\left(E_{a}\right)$ of the material by (1), where $K$ is the Boltzmann constant and $T$ is the temperature:

$$
\mathrm{TCR}=-\frac{E_{a}}{K T^{2}} .
$$

Up to now, amorphous semiconductors have been widely used as thermosensitive materials in commercial microbolometers arrays (IRFPAs). These materials have advantages over other thermosensitive materials, since they are compatible with standard Si CMOS technology and have high $E_{a}$ and high TCR values.

In this aspect, a-Si:H has a direct band gap $(1.6-1.8 \mathrm{eV})$, high activation energy $\left(E_{a}=0.8 \mathrm{eV}\right)$, and very high thermal coefficient of resistance (TCR $=-10 \% \mathrm{~K}^{-1}$ ) and also has a very high room temperature resistivity $\left(\sim 10^{9} \Omega \mathrm{cm}\right)$, which is noncompatible with the Si CMOS ROIC input impedance.

In order to reduce the high resistance of a-Si:H, boron doping has been used. The boron doped a-Si:H films have an improved room temperature conductivity $\left(\sigma_{\mathrm{RT}}\right)$ in several orders of magnitude and also showed a high reduction in $E_{a}(0.22 \mathrm{eV})$ and TCR $\left(-2.8 \% \mathrm{~K}^{-1}\right)[5,6]$. Despite the above, a-Si:H,B has been adopted as IR sensing film for microbolometers contained in very large IRFPAs $(1024 \times 768)$ $[4,6,7]$. Recently, the control of the $\mathrm{BCl}_{3} / \mathrm{SiH}_{4}$ gas flow rate during the a-Si:H,B films deposition by PECVD has been demonstrated, in order to improve the TCR to values as large as $-3.9 \% \mathrm{~K}^{-1}$ [7] 


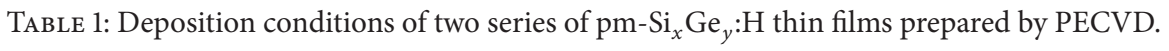

\begin{tabular}{|c|c|c|c|c|c|c|}
\hline & Sample number & Temperature ${ }^{\circ} \mathrm{C}$ & Pressure mTorr & $\mathrm{SiH}_{4} \mathrm{sccm}$ & $\mathrm{GeH}_{4} \mathrm{sccm}$ & $\mathrm{H}_{2} \mathrm{sccm}$ \\
\hline \multirow{3}{*}{ Series \#1 } & P11 & \multirow{6}{*}{$200^{\circ} \mathrm{C}$} & 500 & & & \\
\hline & P12 & & 1000 & 50 & 50 & 110 \\
\hline & P13 & & 1200 & & & \\
\hline \multirow{3}{*}{ Series \#2 } & $\mathrm{P} 21$ & & 500 & \multirow{3}{*}{90} & \multirow{3}{*}{10} & \multirow{3}{*}{110} \\
\hline & P22 & & 1000 & & & \\
\hline & $\mathrm{P} 23$ & & 1200 & & & \\
\hline
\end{tabular}

Among the other materials that have been used in thermal detectors is Vanadium Oxide $\left(\mathrm{VO}_{x}\right)$ which was the first material used in high performance microbolometers, due to its relatively high TCR of $-2 \% \mathrm{~K}^{-1}[8]$; however, this material is not compatible with the $\mathrm{Si}$ CMOS technology.

Amorphous germanium silicon oxide $\left(\mathrm{a}-\mathrm{Ge}_{x} \mathrm{Si}_{1-x} \mathrm{O}_{y}\right)$ deposited by RF sputtering also has been reported with large TCR values of $-4.8 \% \mathrm{~K}^{-1}$ [9] and semiconducting yttrium barium copper oxide (YBCO) has been studied as IR sensing film, with large TCR values of $-3.4 \% \mathrm{~K}^{-1}[10]$.

Recently, nanostructured $\mathrm{VO}_{x}$ films have been reported in microbolometers with very large TCR values of $-5.6 \% \mathrm{~K}^{-1}$ [11]. However, this material is also incompatible with the $\mathrm{Si}$ CMOS process, which restricts its incorporation in very large IRFPAs based on the Si CMOS technology.

On the other hand, even though amorphous semiconductors as a-Si:H,B are the IR sensing materials of choice in the most developed IRFPAs, they have some drawbacks due to their inherent high density of states in band gap, high density of defects, poor transport properties, and poor stability against radiation [12].

Recently, the production of amorphous semiconductors with embedded nanocrystals has been demonstrated; those materials are referenced as polymorphous semiconductors, as polymorphous silicon (pm-Si:H) [12-15], which are mainly investigated for applications in thin film solar cells. The presence of the embedded nanocrystals in the amorphous matrix impacts on the material properties, reducing the density of states and defects and also improving the transport properties and stability against radiation. Moreover, polymorphous semiconductors preserve the characteristic of amorphous semiconductors as direct band gap, high $E_{a}$, and high TCR $[12,13]$.

Polymorphous semiconductors practically have not been used for thermal detection applications; however, they are excellent candidates to be used as thermosensing materials in high performance microbolometers in commercial IRFPAs. In our previous work, we have shown that it is possible to produce $\mathrm{pm}-\mathrm{Si}_{x} \mathrm{Ge}_{y}: \mathrm{H}$ thin films in a Low Frequency Plasma Enhanced Chemical Vapor Deposition (LF-PECVD) reactor working at $110 \mathrm{KHz}$, using $\mathrm{SiH}_{4}$ and $\mathrm{GeH}_{4}$ as precursor gases [16]. However, an LF-PECVD technique is not standard in the microelectronics industry, and moreover in this technique, due to its low frequency, the ions have a contribution in the plasma and the properties of the deposited films can be affected. The ions in the plasma can help to dissociate more effectively the reactive species and also can produce damage in the film, due to ion bombardment. Therefore, the results obtained by LF-PECVD could not be reproducible in a standard PECVD reactor working a radio frequency (RF) of 13.56 MHz, which is used in the microelectronics industry.

In the present work, we studied the deposition of pm-Si $\mathrm{Ge}_{x}: \mathrm{H}$ thin films in a $\mathrm{RF}-\mathrm{PECVD}$ reactor working at a frequency of $13.56 \mathrm{MHz}$. Moreover, we studied the effect of the most important deposition parameters (deposition pressure and $\mathrm{SiH}_{4} / \mathrm{GeH}_{4}$ flow rate ratio) on the electrical, morphological, and optical characteristics of the films, with the objective to produce films with very large $E_{a}$ and TCR, maintaining a moderated resistivity.

\section{Experimental}

We studied the effect of the chamber pressure and the $\mathrm{SiH}_{4} / \mathrm{GeH}_{4}$ flow ratio on the thermal sensitivity (TCR) and $\sigma_{\mathrm{RT}}$ of the resulting films. Two series of silicon- (Si-) germanium (Ge) films were deposited in an industrially compatible capacitively coupled PECVD reactor (from MVSystem Inc.) working at standard radio frequency of $13.56 \mathrm{MHz}$, with a RF power density of $86 \mathrm{~mW} / \mathrm{cm}^{2}$, substrate temperature $\left(T_{s}\right)$ of $200^{\circ} \mathrm{C}$, and three different chamber pressure values (500 mTorr, 1000 mTorr, and 1200 mTorr).

The films of Series \#1 were deposited with the flow rates of the precursors gases $\mathrm{H}_{2}=110 \mathrm{sccm}, \mathrm{SiH}_{4}=50 \mathrm{sccm}$, and $\mathrm{GeH}_{4}$ $=50 \mathrm{sccm}$ (resulting in $\mathrm{SiH}_{4} / \mathrm{GeH}_{4}=1$ ), while the films of Series \#2 were deposited with the flow rates of the precursors gases $\mathrm{H}_{2}=110 \mathrm{sccm}, \mathrm{SiH}_{4}=90 \mathrm{sccm}$, and $\mathrm{GeH}_{4}=10 \mathrm{sccm}$ (resulting in $\mathrm{SiH}_{4} / \mathrm{GeH}_{4}=9$ ). Notice that $\mathrm{SiH}_{4}$ and $\mathrm{GeH}_{4}$ used are diluted at $10 \%$ in $\mathrm{H}_{2}$, and therefore the $\mathrm{H}_{2}$ dilution is high $\left(\mathrm{H}_{2} /\left(\mathrm{SiH}_{4}+\mathrm{GeH}_{4}\right)=20\right)$.

The conditions used for the deposition of both series are summarized in Table 1. Both film series were deposited in various types of substrates for electrical, structural, and compositional characterization. The films depositions were performed simultaneously on corning glass 2974, corning glass 1737, corning glass 2974 with titanium metal contacts, and high resistivity silicon substrates.

Atomic force microscopy (AFM Nanosurf Easy Scan 2.3) was used to analyze the surface roughness of the films and thereby determine the possible presence of nanoclusters presented in the surface of the film. A large surface roughness is an indication of the presence of nanocrystals and even microcrystals in the bulk of the film [17].

Besides AFM characterization, Ultra High Resolution Field Emission Scanning Electron Microscopy (FE-SEM) 


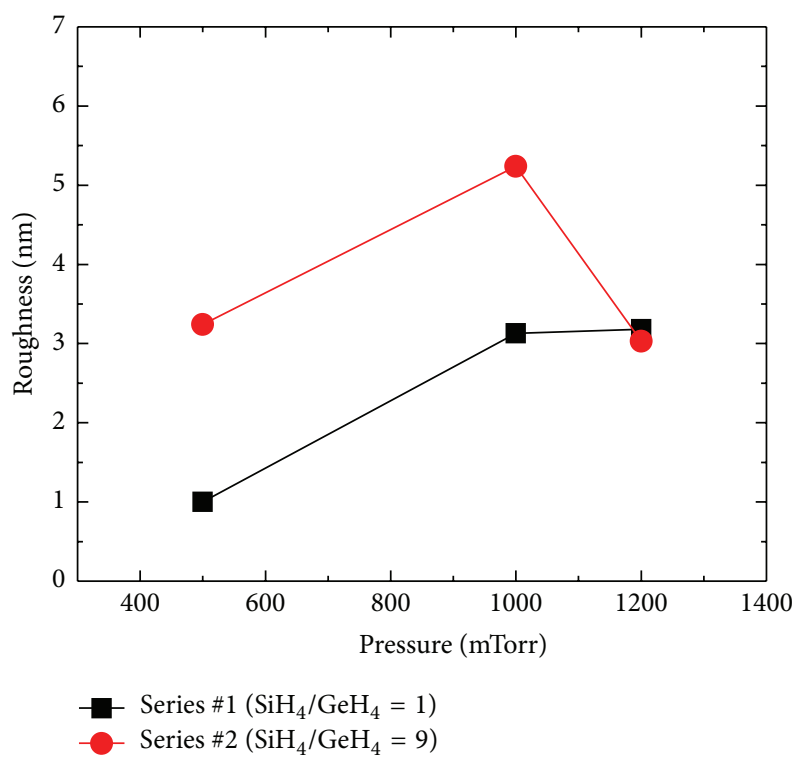

FIGURE 1: Average surface roughness $\left\langle S_{a}\right\rangle$ versus chamber pressure

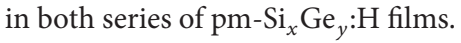

and High Resolution Transmission Electron Microscopy (HRTEM) were used to analyze the films surface and the transversal structure of the films, in order to correlate the AFM results.

Ultraviolet-Visible (UV-Vis) transmittance measurements were performed in a Perkin-Elmer Lambda 3B spectrometer, in the range of $200-900 \mathrm{~nm}$. Those measurements were performed in order to determine optical parameters of the deposited films, as the extinction coefficient $(k)$ and the optical band gap $\left(E_{g}\right)$.

The films also were analyzed on a Fourier Transform Infrared (FTIR) spectrophotometer (Bruker, Vector 22); the FTIR measurements were performed to analyze the molecular composition of the deposited films. For measurements of temperature dependence of the conductivity, the samples were placed in a thermostat with a pressure of 30 mTorr. A temperature controller (331 Temperature Controller, Lakeshore) was used to adjust the sample temperature. The temperature was varied from $300 \mathrm{~K}$ to $400 \mathrm{~K}$, with steps of $10 \mathrm{~K}$. At each temperature step, measurements were made to obtain the current-voltage characteristics $(I(U))$ of the films. With this characterization we obtained the values of $E_{a}$, TCR, and the electrical conductivity at room temperature $\left(\sigma_{\mathrm{RT}}\right)$.

\section{Results and Discussion}

Atomic Force Microscopy (AFM) measurements were performed in order to characterize the surface roughness $\left(\left\langle S_{a}\right\rangle\right)$ of the two film series. Figure 1 shows the dependence of $\left\langle S_{a}\right\rangle$ with the deposition pressure in both films series and we can see that $\left\langle S_{a}\right\rangle$ is larger in the films deposited at pressures in the range of 1000 mTorr-1200 mTorr. The average surface roughness $\left\langle S_{a}\right\rangle$ was obtained from a statistical analysis by scanning an area of $4 \mu \mathrm{m} \times 4 \mu \mathrm{m}$ on the surface of the films.
Figure 2 shows AFM 3D images of film surfaces corresponding to deposition pressures of 500 mTorr, 1000 mTorr, and 1200 mTorr, for both series. In the figure it is observed that the films deposited at pressure of 500 mTorr have a flatter surface (and lower roughness) than those films deposited at 1000 mTorr and 1200 mTorr. In this aspect, it is important to stress that the AFM technique is used for correlating the surface roughness to the presence of nanocrystals in the bulk. Large $\left\langle S_{a}\right\rangle$ is related to the presence of micro/nanocrystals embedded in the amorphous network. $\left\langle S_{a}\right\rangle$ of about $4 \mathrm{~nm}$ (and higher) is an indication of the presence of nanocrystals in the amorphous matrix [17]; however, this technique by itself is not enough for completely determining the structural composition of the bulk material.

Figure 3 shows an ultrahigh resolution FE-SEM image of the surface of a film (with $\left\langle S_{a}\right\rangle$ of about $5 \mathrm{~nm}$ ); in the figure the presence of Si-Ge nanoclusters of sizes of about $50 \mathrm{~nm}$ is observed. In Figure 4, a HRTEM cross section view of the same film is shown, which was deposited on corning glass (a line was drawn for separating the film from the substrate). Several nanocrystals of size of about $2 \mathrm{~nm}-3 \mathrm{~nm}$ are marked and also an inset of the amplified image of 2 nanocrystals is included. The above analysis is in agreement with the AFM results and indicates the polymorphous nature of the film.

Figure 5 shows the deposition rate $\left(V_{d}\right)$ as a function of the deposition pressure in both $\mathrm{pm}-\mathrm{Si}_{x} \mathrm{Ge}_{y}: \mathrm{H}$ film series. For Series \#1, $V_{d}$ was in the range $0.79 \AA / \mathrm{s}-2.72 \AA / \mathrm{s}$, while, for Series \#2, $V_{d}$ was in the range $1 \AA / s-1.5 \AA / s$. For Series $\# 1$, the largest $V_{d}$ was obtained in the film deposited at chamber pressure of 1200 mTorr, while, for Series \#2, the largest $V_{d}$ was obtained in the film deposited at chamber pressure of 1000 mTorr. It has been observed that high deposition rates are associated with large crystalline fractions in microcrystalline films [18]. This is related to the fact that, at large $V_{d}$, the oxygen incorporation in the film is reduced, and the formation of nanocrystals in the plasma is promoted.

Ultraviolet-Visible (UV-Vis) transmittance measurements were performed for determining the band gap $\left(E_{g}\right)$ of the $\mathrm{pm}-\mathrm{Si}_{x} \mathrm{Ge}_{y}: \mathrm{H}$ films. From the transmittance measurements, we obtained a data file that was processed using PUMA (Pointwise Unconstrained Minimization Approach). The software provides information of the characteristics of the films related to transmittance data measurements [19]. The important data obtained from PUMA is the extinction coefficient $(k)$, which is converted to absorption coefficient $(\alpha)$ by

$$
\alpha=\frac{4 \pi k}{\lambda} .
$$

Figure 6 shows the Tauc plots of both series of pm- $\mathrm{Si}_{x} \mathrm{Ge}_{y}: \mathrm{H}$ films. We can determine $E_{g}$ from the Tauc plot, where $E_{g}$ is extracted by the extrapolation of the linear part of the plot towards the energy axis, and the interception indicates $E_{g}$ of the film. In the films of Series \#1, the $E_{g}$ values are in the range $1.2 \mathrm{eV}-1.28 \mathrm{eV}$, while, in the films of Series \#2, the $E_{g}$ values are in the range $1.37 \mathrm{eV}-1.66 \mathrm{eV}$. The above is related to the $\mathrm{Si}$ and $\mathrm{Ge}$ content in the films; for Series \#1, the Ge content is larger than in Series \#2 (due to a 
Series \#1

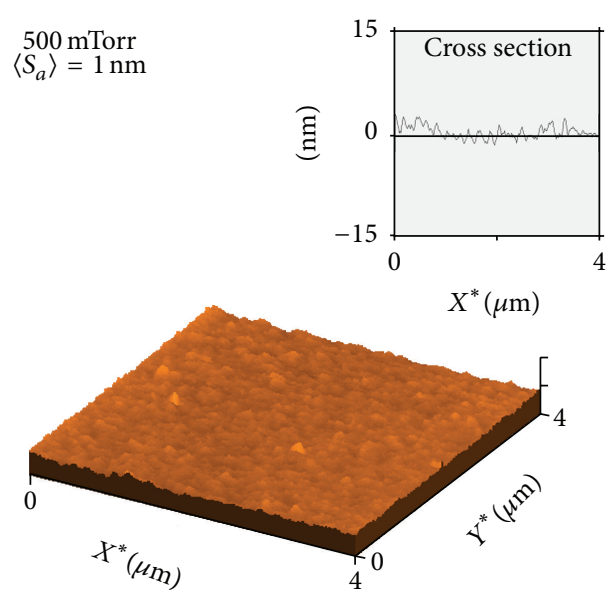

(a)

Series \#1

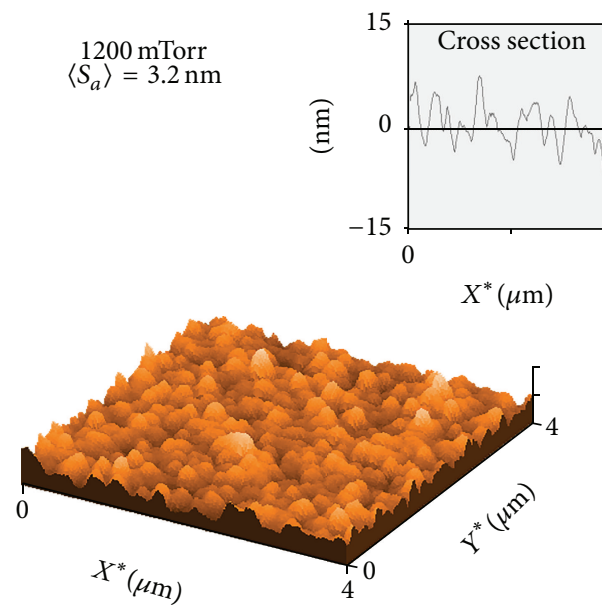

(c)

Series \#2
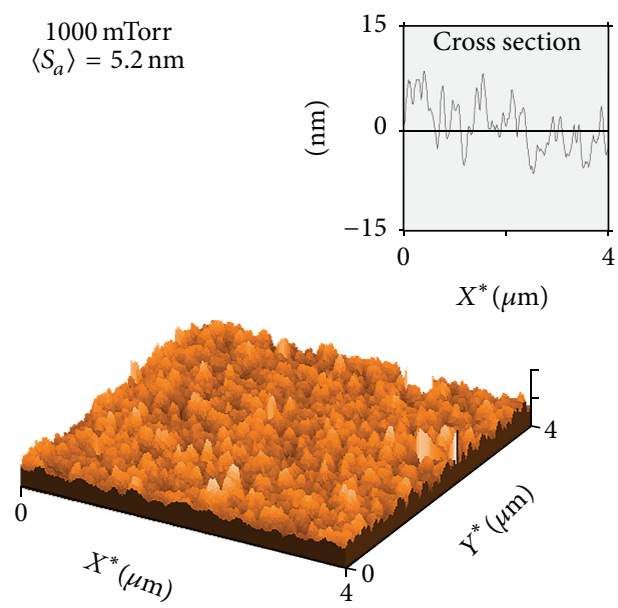

(e)
Series \#1
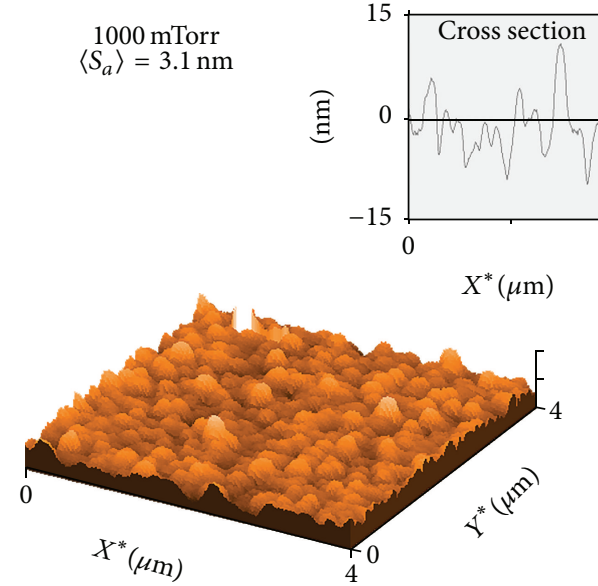

(b)

Series \#2

$$
\begin{gathered}
500 \text { mTorr } \\
\left\langle S_{a}\right\rangle=3.2 \mathrm{~nm}
\end{gathered}
$$
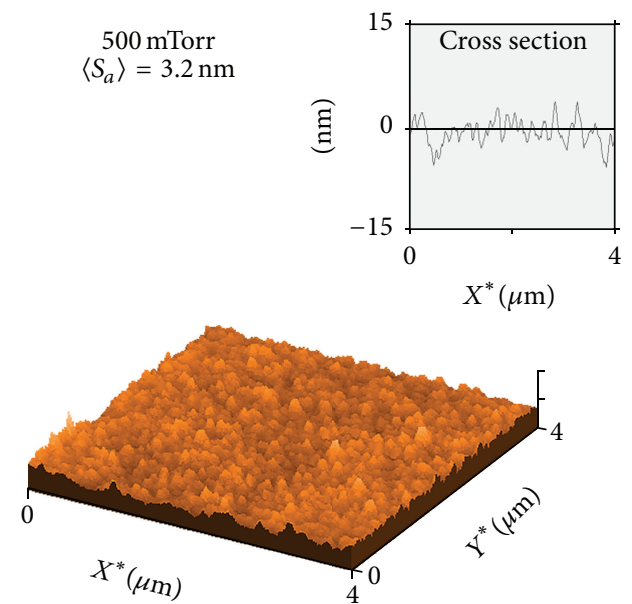

(d)

Series \#2
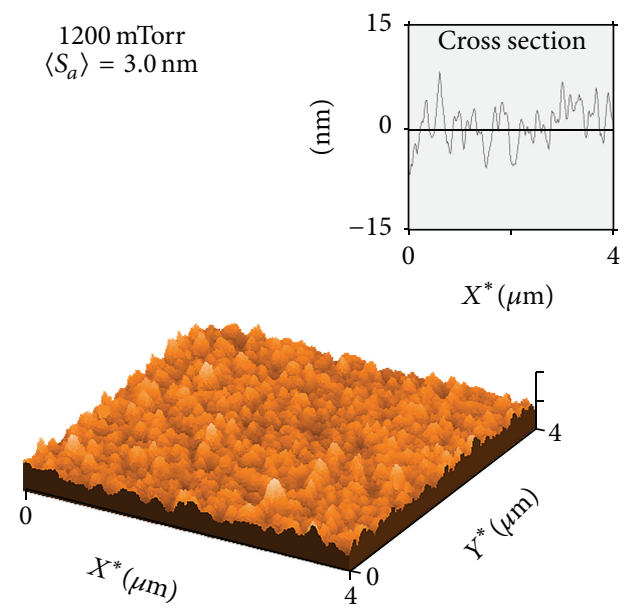

(f)

FIGURE 2: Surface analysis by AFM in pm-Si $\mathrm{Ge}_{y}: \mathrm{H}$ films, corresponding to (a) Series \#1: 500 mTorr, (b) Series \#1: $1000 \mathrm{mTorr}$, (c) Series \#1: 1200 mTorr. (d) Series \#2: 500 mTorr, (e) Series \#2: 1000 mTorr, and (f) Series \#2: 1200 mTorr. 


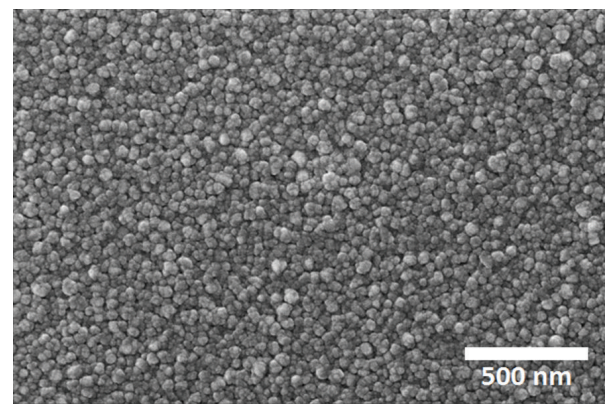

Figure 3: FE-SEM image of the surface of a pm-Si $\mathrm{Ge}_{y}: \mathrm{H}$ film, where the presence of nanoclusters of sizes of about $50 \mathrm{~nm}$ is observed.

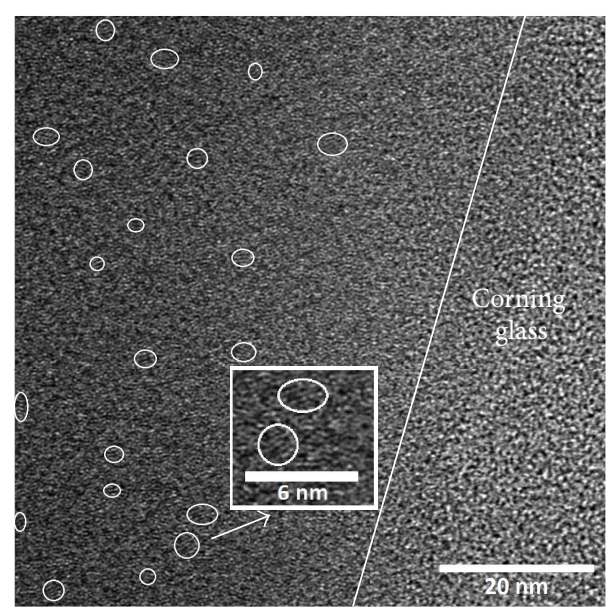

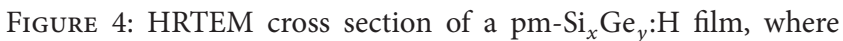
the presence of nanocrystals of sizes in the range of $2 \mathrm{~nm}-3 \mathrm{~nm}$ is observed. The inset shows an amplified image of 2 nanocrystals.

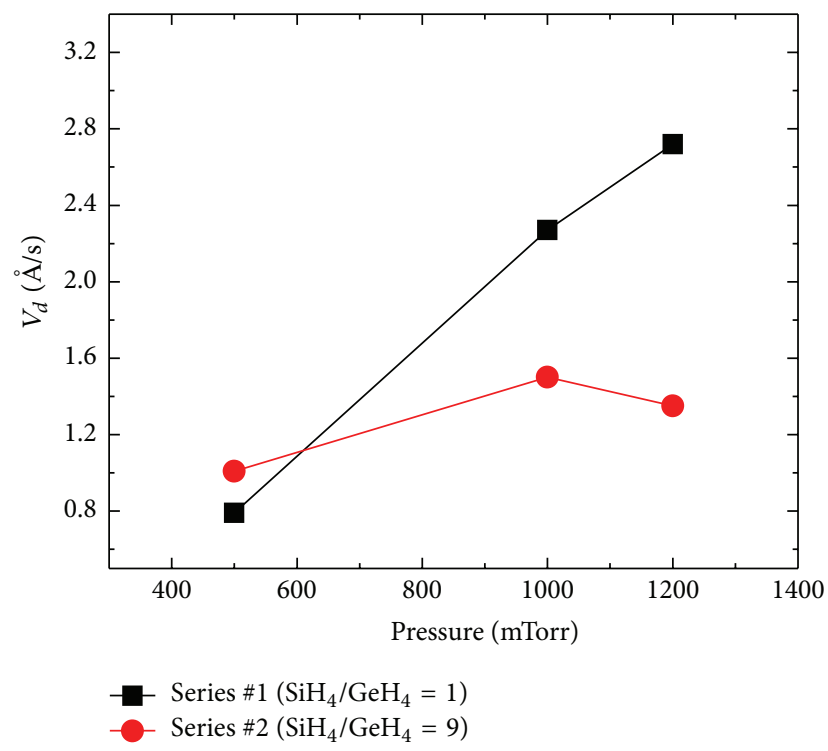

FIgURE 5: Deposition rate $\left(V_{d}\right)$ in two series of deposited films. Series \#1: $\mathrm{SiH}_{4} / \mathrm{GeH}_{4}=1$ and Series \#2: $\mathrm{SiH}_{4} / \mathrm{GeH}_{4}=9$. larger $\mathrm{GeH}_{4}$ flow rate used for deposition). In this aspect, it has been reported for amorphous silicon-germanium films (a-SiGe:H) that a flow rate ratio of $\mathrm{SiH}_{4} / \mathrm{GeH}_{4}=1$ results in films with solid $\mathrm{Ge}$ content of about $85 \%$, while a flow rate ratio of $\mathrm{SiH}_{4} / \mathrm{GeH}_{4}=9$ results in films with solid Ge content of about 45\%; that analysis was performed using Secondary Ion Mass Spectroscopy (SIMS) [20].

The films were also analyzed with a FTIR spectrophotometer, which provides a spectrum of absorbance (or transmittance) in arbitrary units. In Figure 7 , we observe the absorption spectra of both series of $\mathrm{pm}-\mathrm{Si}_{x} \mathrm{Ge}_{y}: \mathrm{H}$ films in the range from $400 \mathrm{~cm}^{-1}$ to $2200 \mathrm{~cm}^{-1}$. It is observed that both FTIR spectra are very similar; the most relevant peaks of both spectra are described below.

In the region between $500 \mathrm{~cm}^{-1}$ and $700 \mathrm{~cm}^{-1}$ there are two peaks centered at $560 \mathrm{~cm}^{-1}$ and at $640 \mathrm{~cm}^{-1}$, which are related to the $\mathrm{Ge}-\mathrm{H}$ and $\mathrm{Si}-\mathrm{H}$ bending vibration modes, respectively [21]. The peak near to $735 \mathrm{~cm}^{-1}$ is related to GeO bonds, while the peak near to $885 \mathrm{~cm}^{-1}$ is related to Si$\mathrm{H}$ bonds. Near to $960 \mathrm{~cm}^{-1}$ there is a peak related to Ge$\mathrm{O}$ bonds and at $1100 \mathrm{~cm}^{-1}$ there is a peak related to $\mathrm{Si}-\mathrm{O}$ bonds. Finally near to $2000 \mathrm{~cm}^{-1}$ there is a peak attributed to a $\mathrm{Si}-\mathrm{H}$ stretching mode. All these peaks are present in both spectra.

The absorption peak near $1880 \mathrm{~cm}^{-1}$ is attributed to the stretching vibration of Ge-H [20]; this peak is only present in the spectra of the films of Series \#1, indicating a higher Ge content (than in the films of Series \#2). The above is in agreement with the band gap analysis (Tauc plot) and the larger $\mathrm{GeH}_{4}$ flow rate used for the deposition of Series \#1.

In Figure 8, the dependence of $\sigma_{\mathrm{RT}}$ as a function of the deposition pressure in both series of $\mathrm{pm}-\mathrm{Si}_{x} \mathrm{Ge}_{y}: \mathrm{H}$ films is shown, and it is observed that $\sigma_{\mathrm{RT}}$ is larger in the films deposited at pressure in the range of 1000 mTorr-1200 mTorr. The above result is very interesting, since it indicates that deposition pressures, in that range, promote films with better structural order, due to the presence of nanocrystals, and those nanocrystals improve the electron mobility in the films $\left(\mu_{e}\right)$ and consequently $\sigma_{\mathrm{RT}}$.

In Figure 8, it is also observed that the films of Series $\# 1\left(\mathrm{SiH}_{4} / \mathrm{GeH}_{4}=1\right)$ have larger $\sigma_{\mathrm{RT}}$ of nearly two orders of magnitude with respect to the films of Series $\# 2\left(\mathrm{SiH}_{4} / \mathrm{GeH}_{4}=\right.$ 9), which is related to the $\mathrm{GeH}_{4}$ flow rate used for deposition (and higher Ge content).

We measured the temperature dependence of conductivity, $\sigma(T)$, in both series of $\mathrm{pm}-\mathrm{Si}_{x} \mathrm{Ge}_{y}: \mathrm{H}$ films, as is shown in Figure 9. We determined $E_{a}$ from the Arrhenius curve $\ln$ (conductivity) versus $1 / K T^{2} . E_{a}$ is related to the conductivity by (3), rewritten in (4), which express a line of the form $y=a+b x$. Then, $E_{a}$ is obtained by fitting a straight line in the curve and calculating its slope as follows:

$$
\begin{array}{r}
\sigma=\sigma_{0} \exp \left(-\frac{E_{a}}{K T^{2}}\right), \\
\ln (\sigma)=\ln \left(\sigma_{0}\right)-\frac{E_{a}}{K T^{2}} .
\end{array}
$$




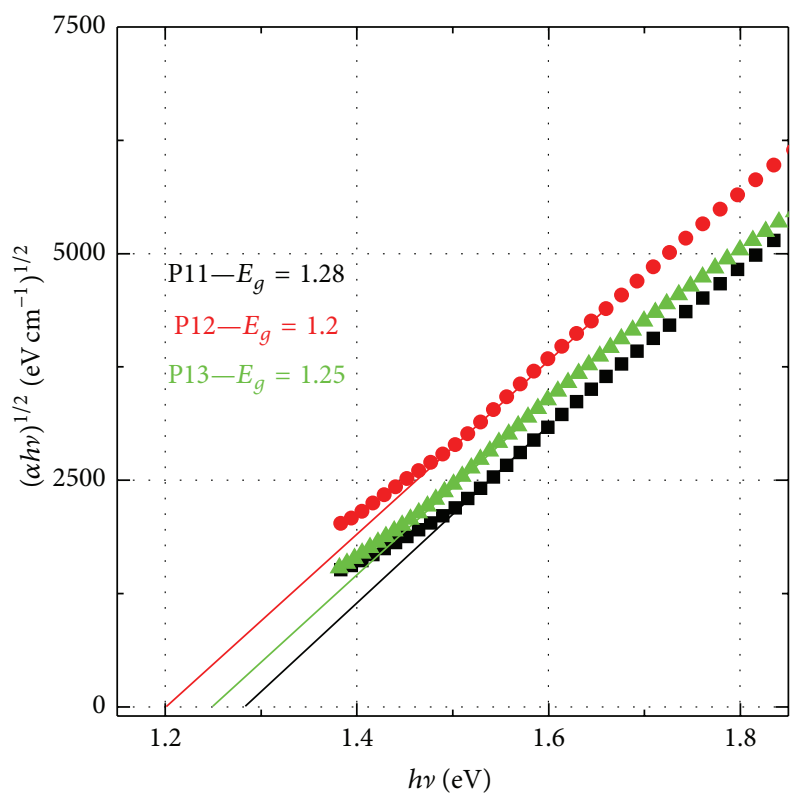

$-\square-\mathrm{P} 11$

$-\bullet$ P12

$-\Lambda-\mathrm{P} 13$

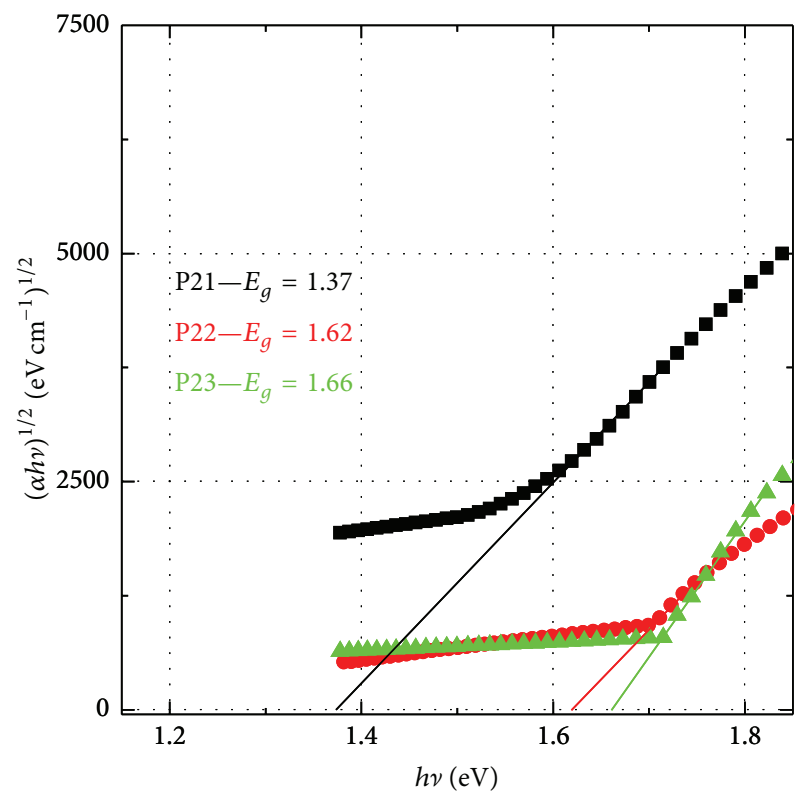

$-\square-\mathrm{P} 21$
$--\mathrm{P} 22$
$-1-\mathrm{P} 23$

(a)

(b)

FiguRE 6: Tauc plot obtained from UV-Vis measurements for extracting the band gap $\left(E_{q}\right)$ in two series of pm-Si $\mathrm{Ge}_{x}: \mathrm{H}_{\text {films. }}$ (a) Series \#1: $\mathrm{SiH}_{4} / \mathrm{GeH}_{4}=1$ and (b) Series \#2: $\mathrm{SiH}_{4} / \mathrm{GeH}_{4}=9$.

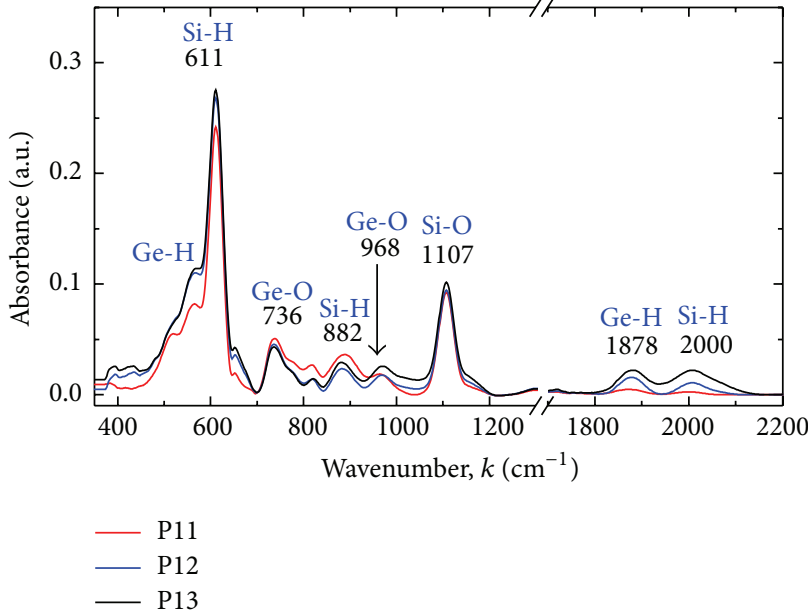

(a)

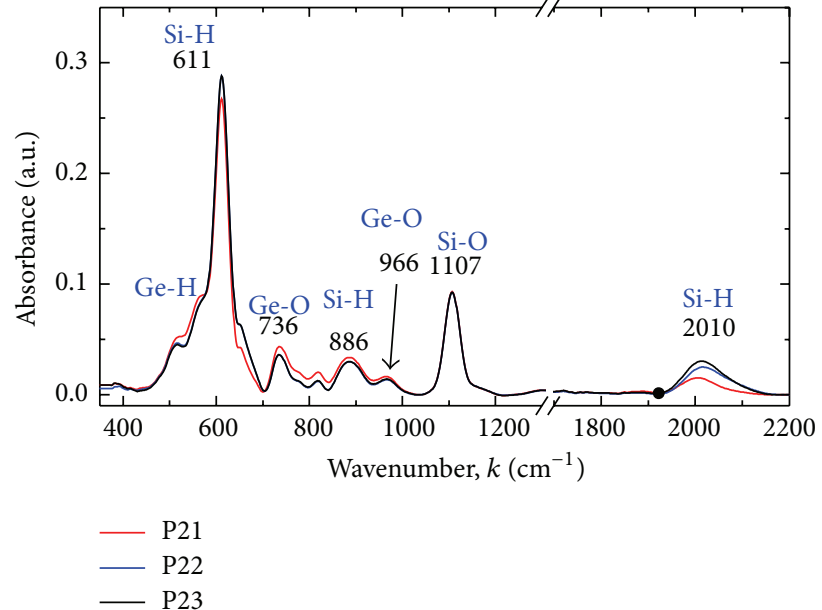

(b)

FIGURE 7: FTIR spectra of two series of pm-Si $\mathrm{Ge}_{y}: \mathrm{H}$ films. (a) Series \#1: $\mathrm{SiH}_{4} / \mathrm{GeH}_{4}=1$ and (b) Series \#2: $\mathrm{SiH}_{4} / \mathrm{GeH}_{4}=9$.

Figure 10 shows $E_{a}$ and TCR as a function of the deposition pressure of both series of $\mathrm{pm}-\mathrm{Si}_{x} \mathrm{Ge}_{y}: \mathrm{H}$ films. For Series $\# 1$, the largest values obtained were $E_{a}=0.45 \mathrm{eV}$ and TCR = $5.9 \% \mathrm{~K}^{-1}$, while, for Series \#2, the largest values obtained were $E_{a}=0.62 \mathrm{eV}$ and TCR $=7.9 \% \mathrm{~K}^{-1}$. The above is related to the fact that the films of Series \#2 were deposited with larger $\mathrm{SiH}_{4}$ flow rate (and consequently have larger Si content) than the films of series \#1.
Finally, after studying the effect of the deposition pressure and the $\mathrm{SiH}_{4} / \mathrm{GeH}_{4}$ flow rate ratio on the characteristics of $\mathrm{pm}-\mathrm{Si}_{x} \mathrm{Ge}_{y}: \mathrm{H}$ films, we can conclude that large pressure values (1000 mTorr-1200 mTorr) are suitable for the formation of nanocrystals in the amorphous films, improving their stability and electrical characteristics. On the other hand, depending on the $\mathrm{SiH}_{4} / \mathrm{GeH}_{4}$ flow rate ratio used for the films deposition, it is possible to produce films with TCR values 


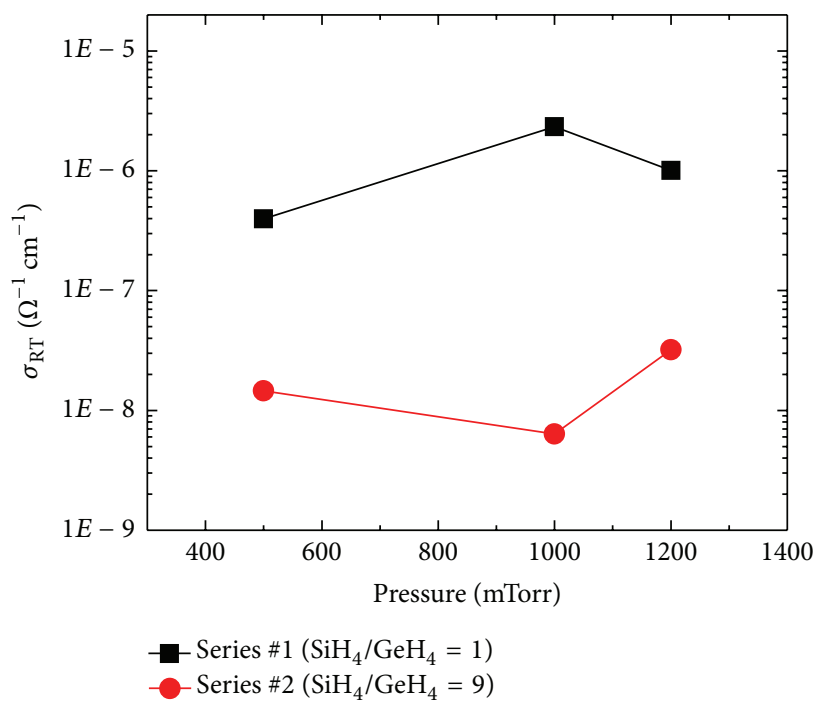

Figure 8: Room temperature conductivity $\left(\sigma_{\mathrm{RT}}\right)$ in two series of pm-Si $\mathrm{Ge}_{y}: \mathrm{H}$ deposited films. Series \#1: $\mathrm{SiH}_{4} / \mathrm{GeH}_{4}=1$ and Series \#2: $\mathrm{SiH}_{4} / \mathrm{GeH}_{4}=9$.

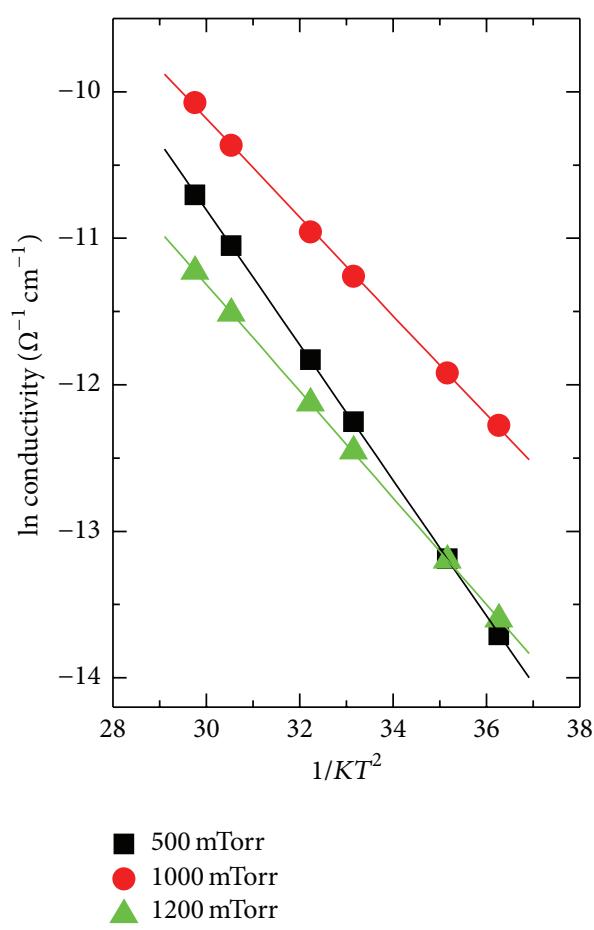

(a)

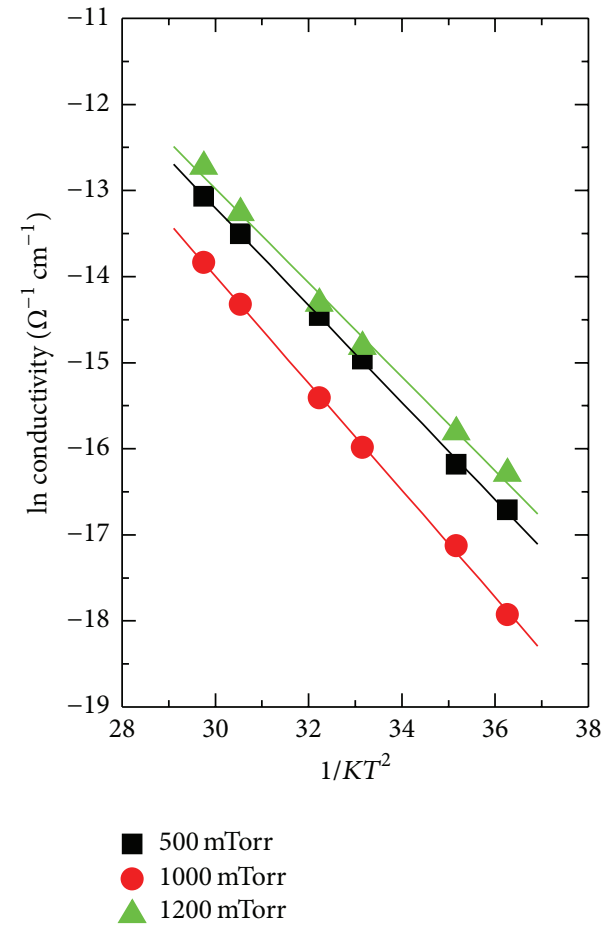

(b)

Figure 9: Temperature dependence of conductivity, $\sigma(T)$, in two series of pm-Si $\mathrm{Ge}_{y}: \mathrm{H}$ films. (a) Series \#1: $\mathrm{SiH}_{4} / \mathrm{GeH}_{4}=1$ and (b) Series \#2: $\mathrm{SiH}_{4} / \mathrm{GeH}_{4}=9$.

in the range of $4.3 \% \mathrm{~K}^{-1}-7.9 \% \mathrm{~K}^{-1}$, with moderated $\sigma_{\mathrm{RT}}$. The above characteristics are better than those of a-Si:H,B films used in commercial IRFPAs.

\section{Conclusion}

In this work, we have studied the deposition and characterization of amorphous silicon-germanium films with embedded nanocrystals $\left(\mathrm{pm}-\mathrm{Si}_{x} \mathrm{Ge}_{y}: \mathrm{H}\right)$. We have studied the films characteristics under the influence of the deposition parameters as the chamber pressure and the precursor gases flow rate ratios $\left(\mathrm{SiH}_{4} / \mathrm{GeH}_{4}\right)$. We have concluded that there is an optimum deposition pressure that promotes the formation of nanocrystals in the amorphous films (1000 mTorr1200 mTorr) and impacts on the electrical characteristics and stability of the films. On the other hand, by varying the 


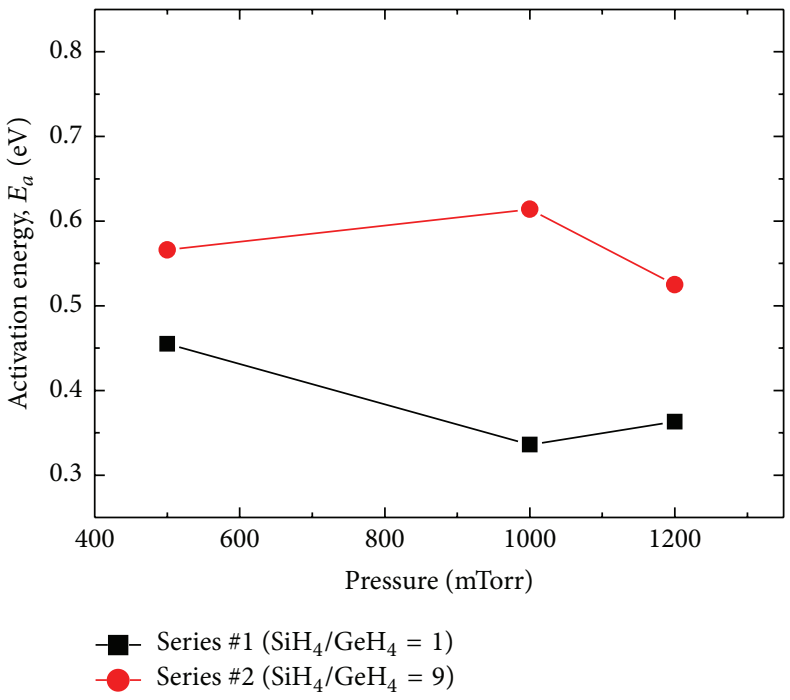

(a)

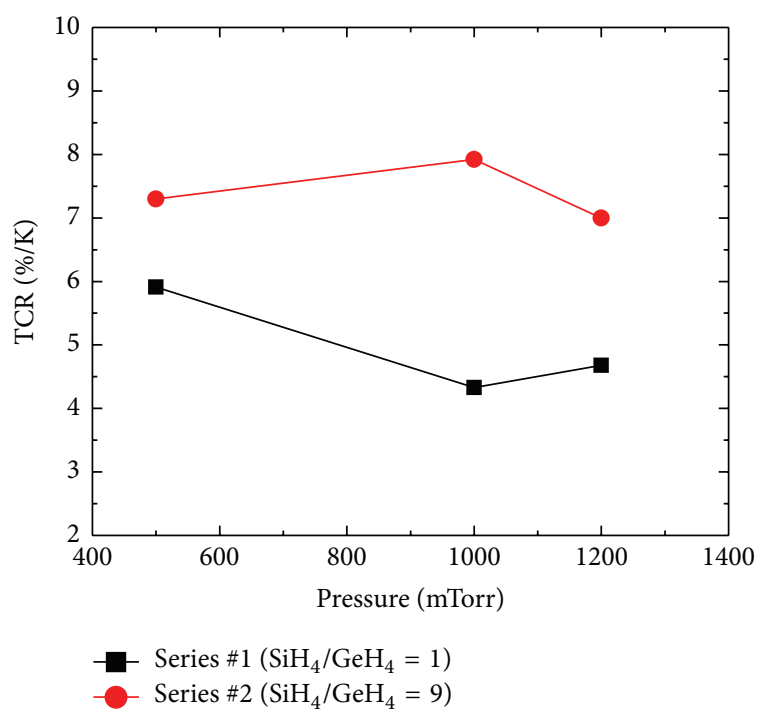

(b)

Figure 10: (a) Activation energy $\left(E_{a}\right)$ as a function of the deposition pressure of two series of pm- $\mathrm{Si}_{x} \mathrm{Ge}_{y}: \mathrm{H}$ films. (b) TCR as a function of the deposition pressure for two series of $\mathrm{pm}-\mathrm{Si}_{x} \mathrm{Ge}_{y}$ films.

$\mathrm{SiH}_{4} / \mathrm{GeH}_{4}$ flow rate ratio, it is possible to vary $\sigma_{\mathrm{RT}}$ of the films (in about two orders of magnitude), as well the TCR in the range of $4.3 \% \mathrm{~K}^{-1}-7.9 \% \mathrm{~K}^{-1}$.

Finally, we conclude that $\mathrm{pm}-\mathrm{Si}_{x} \mathrm{Ge}_{y}: \mathrm{H}$ films have advantages over amorphous thin films based on boron doped a$\mathrm{Si}: \mathrm{H}$, due to their very large values of TCR with moderated values of $\sigma_{\mathrm{RT}}$ and, moreover, due to the possibility of tailoring those characteristics for specific requirements.

\section{Conflict of Interests}

The authors declare that there is no conflict of interests regarding the publication of this paper.

\section{References}

[1] A. Rogalski, "Recent progress in infrared detector technologies," Infrared Physics \& Technology, vol. 54, no. 3, pp. 136-154, 2011.

[2] A. Rogalski, "History of infrared detectors," Opto-electronics Review, vol. 20, no. 3, pp. 279-308, 2012.

[3] S. K. Ajmera, A. J. Syllaios, G. S. Tyber, M. F. Taylor, and R. E. Hollingsworth, "Amorphous silicon thin-films for uncooled infrared microbolometer sensors," in Proceedings of the Infrared Technology and Applications XXXVI, vol. 7660 of Proceedings of SPIE, p. 766012, Orlando, Fla, USA, May 2010.

[4] B. Fièque, J. L. Tissot, C. Trouilleau, A. Crastes, and O. Legras, "Uncooled microbolometer detector: recent developments at Ulis," Infrared Physics and Technology, vol. 49, no. 3, pp. 187-191, 2007.

[5] A. Heredia-J, A. Torres-J, A. Jaramillo-N, F. J. De la HidalgaW, and M. Landa-V, "A boron doped amorphous silicon thinfilm bolometer for long wavelength detection," in Progress in Semiconductors II-Electronic and Optoelectronic Applications, B. D. Weaver, M. O. Manaresh, C. C. Jagadish, and S. Zollner,
Eds., vol. 744 of MRS Proceedings, Materials Research Society, 2002.

[6] A. J. Syllaios, T. R. Schimert, R. W. Gooch, W. L. McCardel, B. A. Ritchey, and J. H. Tregilgas, "Amorphous silicon microbolometer technology," in Proceedings of the Material Research Society Symposium, R. W. Collins, H. M. Branz, S. Guha, H. Okamoto, and M. Stutzmann, Eds., vol. 609, San Francisco, Calif, USA, 2000, A14.4.1.

[7] S. K. Ajmera, A. J. Syllaios, G. S. Tyber, M. F. Taylor, and R. E. Hollingsworth, "Amorphous silicon thin-films for uncooled infrared microbolometer sensors," in Infrared Technology and Applications XXXVI, vol. 7660 of Proceedings of SPIE, Orlando, Fla, USA, April 2010.

[8] B. E. Cole, R. E. Higashi, and R. A. Wood, "Monolithic two-dimensional arrays of micromachined microstructures for infrared applications," Proceedings of the IEEE, vol. 86, no. 8, pp. $1679-1686,1998$

[9] A. H. Z. Ahmed and R. N. Tait, "Characterization of an amorphous $\mathrm{Ge}_{x} \mathrm{Si}_{1-x} \mathrm{O}_{y}$ microbolometer for thermal imaging applications," IEEE Transactions on Electron Devices, vol. 52, no. 8, pp. 1900-1906, 2005.

[10] A. Jahanzeb, C. M. Travers, Z. Çelik-Butler, D. P. Butler, and S. G. Tan, "A semiconductor $\mathrm{YBaCuO}$ microbolometer for room temperature IR imaging," IEEE Transactions on Electron Devices, vol. 44, no. 10, pp. 1795-1801, 1997.

[11] B. Wang, J. Lai, H. Li, H. Hu, and S. Chen, "Nanostructured vanadium oxide thin film with high TCR at room temperature for microbolometer," Infrared Physics and Technology, vol. 57, pp. 8-13, 2013.

[12] W. Bronner, J. P. Kleider, R. Brüggemann, P. Roca i Cabarrocas, D. Mencaraglia, and M. Mehring, "Comparison of transport and defects properties in hydrogenated polymorphous and amorphous silicon," Journal of Non-Crystalline Solids, vol. 299302, no. 1, pp. 551-555, 2002.

[13] P. Roca i Cabarrocas, A. Fontcuberta i Morral, and Y. Poissant, "Growth and optoelectronic properties of polymorphous silicon thin films," Thin Solid Films, vol. 403-404, pp. 39-46, 2002. 
[14] M. Meaudre, R. Meaudre, R. Butté et al., "Midgap density of states in hydrogenated polymorphous silicon," Journal of Applied Physics, vol. 86, no. 2, pp. 946-950, 1999.

[15] L. Boufendi, M. Ch. Jouanny, E. Kovacevic, J. Berndt, and M. Mikikian, "Dusty plasma for nanotechnology," Journal of Physics D: Applied Physics, vol. 44, no. 17, Article ID 174035, 2011.

[16] M. Moreno, A. Torres, C. Calleja et al., "Exploring the infraredsensing properties of polymorphous silicon-germanium (pmSixGey:H) thin films," Canadian Journal of Physics, vol. 92, no. 7-8, pp. 565-569, 2014.

[17] A. Shaha, E. Vallat-Sauvain, P. Torres et al., "Intrinsic microcrystalline silicon ( $\mu \mathrm{c}-\mathrm{Si}: \mathrm{H}$ ) deposited by VHF-GD (very high frequency-glow discharge): a new material for photovoltaics and optoelectronics," Materials Science and Engineering B, vol. 69-70, pp. 219-226, 2000.

[18] M. Moreno, R. Boubekri, and P. Roca i Cabarrocas, "Study of the effects of different fractions of large grains of $\mu \mathrm{c}-\mathrm{Si}: \mathrm{H}: \mathrm{F}$ films on the infrared absorption on thin film solar cells," Solar Energy Materials \& Solar Cells, vol. 100, pp. 16-20, 2012.

[19] E. G. Birgin, I. Chambouleyron, and J. M. Martínez, "Estimation of optical constants of thin films using unconstrained optimization," Journal of Computational Physics, vol. 151, pp. 862-880, 1999.

[20] A. Kosarev, A. Torres, Y. Hernandez et al., "Silicon-germanium films deposited by low-frequency plasma-enhanced chemical vapor deposition: effect of $\mathrm{H}_{2}$ and Ar dilution," Journal of Materials Research, vol. 21, no. 1, pp. 88-104, 2006.

[21] X. Liao, H. Povolny, P. Agarwal, and X. Deng, "Raman and IR study of narrow bandgap a-SiGe and $\mu \mathrm{c}-\mathrm{SiGe}$ films deposited using different hydrogen dilution," in Proceedings of the Conference Record of the 29th IEEE Photovoltaic Specialists Conference, pp. 1150-1153, May 2002. 

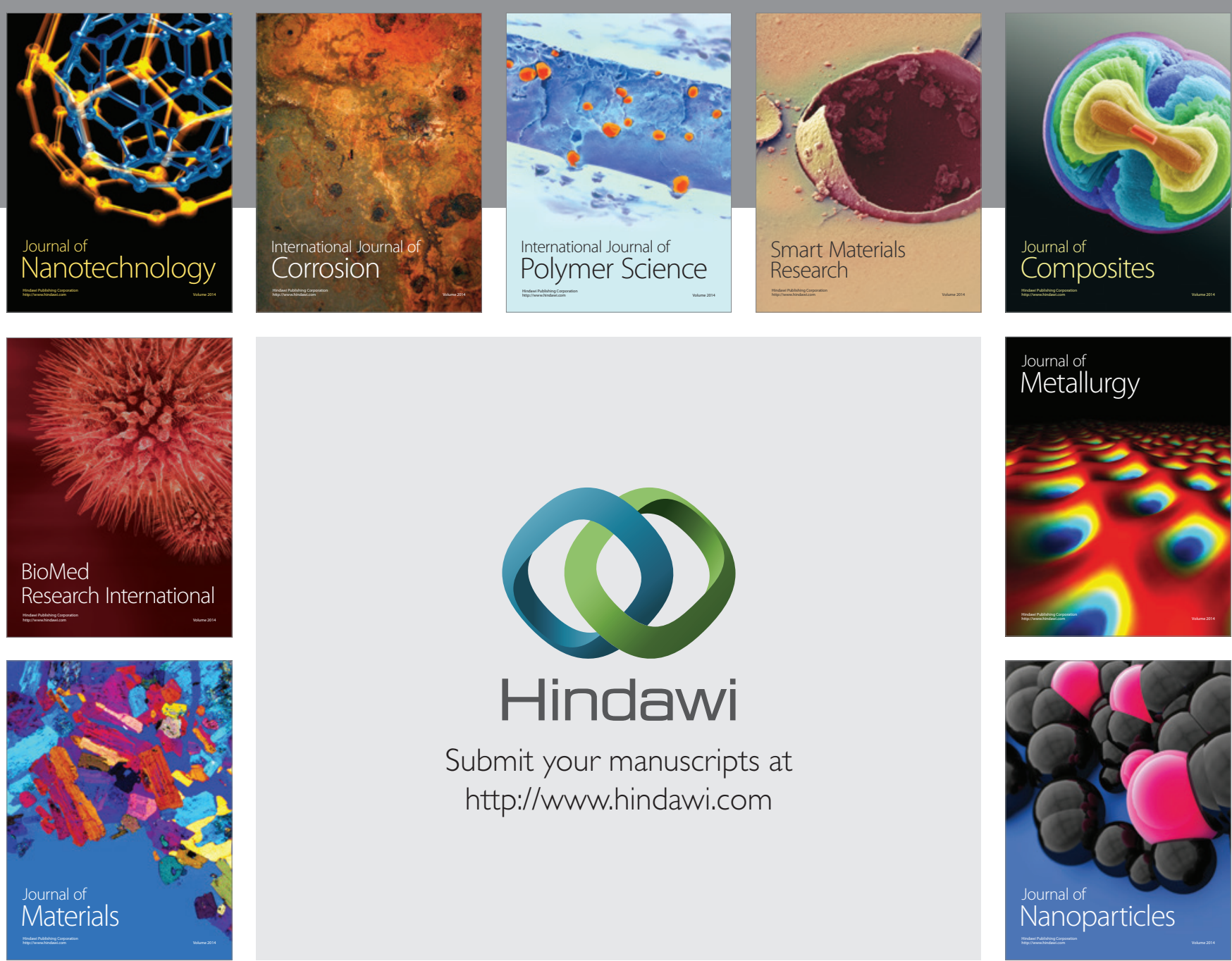

\section{Hindawi}

Submit your manuscripts at

http://www.hindawi.com

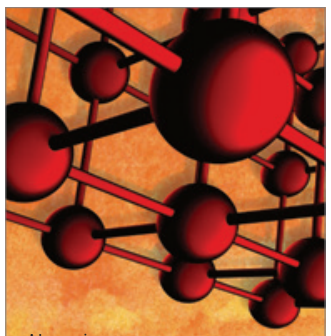

Materials Science and Engineering
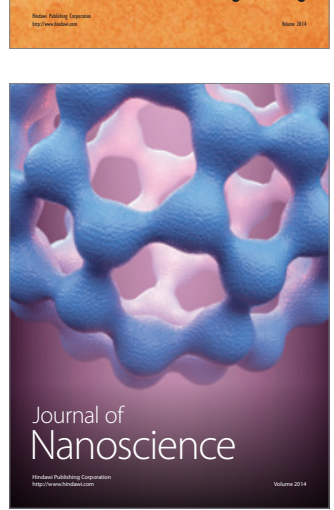
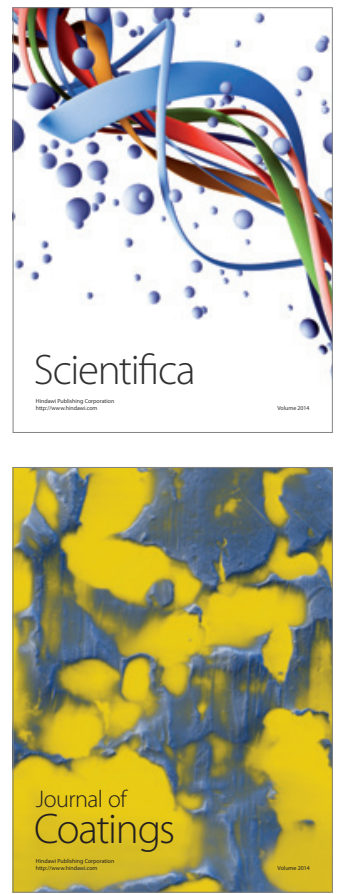
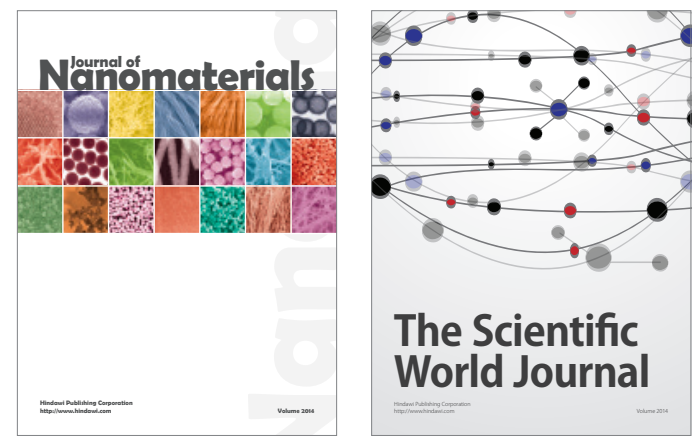

The Scientific World Journal
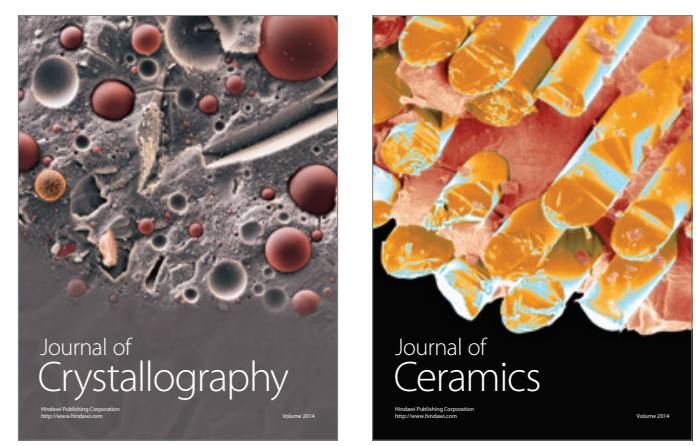
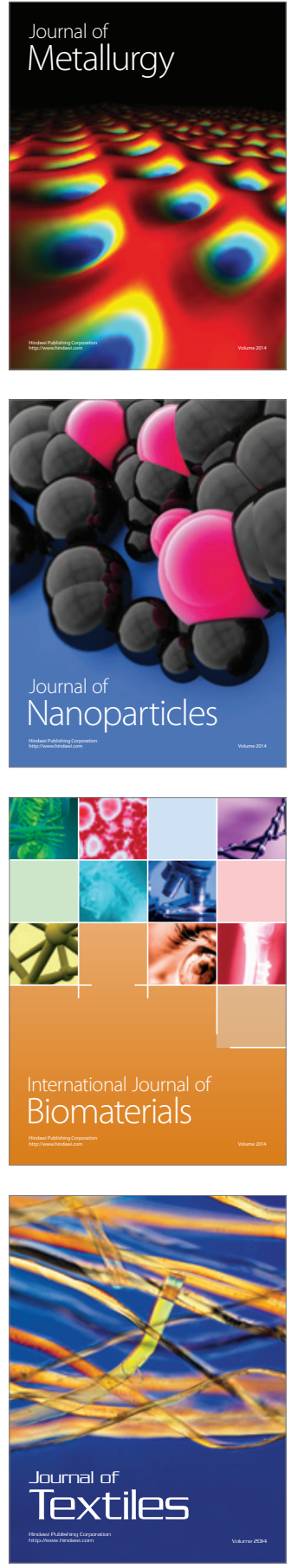